\title{
Colorectal cancer survivors' beliefs on nutrition and cancer; correlates with nutritional information provision
}

\author{
Merel R. van Veen ${ }^{1,2}\left[\right.$ - Floortje Mols ${ }^{3} \cdot$ Lian Smeets $^{1} \cdot$ Ellen Kampman ${ }^{1} \cdot$ Sandra Beijer $^{2}$
}

Received: 13 March 2019 / Accepted: 7 June 2019 / Published online: 21 June 2019

(C) The Author(s) 2019

\begin{abstract}
Purpose To investigate CRC survivors' beliefs on nutrition and cancer and the association with nutritional information provision by (kind and number) of health professionals and to inquire about foods that CRC survivors believed either had a positive or negative influence on their cancer.

Methods A total of 326 CRC survivors of an ongoing prospective cohort study filled out questionnaires 1 month after surgery on whether they had received nutritional information from health professionals. Also, their beliefs that nutrition influences (1) feelings of well-being, (2) complaints after treatment, (3) recovery and (4) cancer recurrence were investigated. Prevalence ratios were calculated (using Cox proportional hazard regression analysis) to study associations between information provision and the four beliefs adjusted for age, gender and cancer stage.

Results Sixty-two percent of respondents received information about nutrition from one or more health professionals. Most respondents who received information strongly believe nutrition influences feelings of well-being (59\%) and recovery after cancer (62\%). Compared with those who did not receive information, respondents who received information from three professionals showed the strongest beliefs on the influence of nutrition on complaints after treatment (PR 3.4; 95\% CI 1.6-7.4), recovery after treatment (PR 2.0; 95\% CI 1.2-3.3) and recurrence (PR 2.8; 95\% CI 1.3-6.2).

Conclusion Nutritional information provision by health professionals positively influences the beliefs of CRC survivors on the influence of nutrition on cancer outcomes: stronger beliefs occur when respondents received information from three health professionals.
\end{abstract}

Keywords Colorectal cancer survivor $\cdot$ Nutrition $\cdot$ Information provision $\cdot$ Health professionals

\section{Introduction}

Colorectal cancer (CRC) is the third most common cancer worldwide [1]. Due to the ageing of the population, implementation of screening programs and ongoing advancements in treatment, incidence and survival rates of CRC have increased over the past years [2], resulting in an increase in CRC survivors [3]. A person

Merel R. van Veen

merelrvanveen@gmail.com

1 Division of Human Nutrition and Health, Wageningen University, P.O. Box 17, 6700 AA Wageningen, The Netherlands

2 Department of Research \& Development Netherlands Comprehensive Cancer Organisation (IKNL),

Utrecht, The Netherlands

3 CoRPS-Center of Research on Psychology in Somatic diseases, Department of Medical and Clinical Psychology, Tilburg University, Tilburg, The Netherlands is characterized as a cancer survivor from the moment of diagnosis until the person deceases [4].

Before, during and after treatment, CRC survivors often suffer from nutrition-related symptoms such as changes in defecation, intestinal cramps, lack of appetite and unintended weight gain or weight loss $[5,6]$, which have a negative impact on quality of life $[7,8]$. Dietary guidelines to alleviate these symptoms are available $[6,7,9]$ and it is important that CRC survivors are able to access and follow this information in order to change their diet to improve their quality of life.

In addition, prospective cohort studies in cancer survivors have shown that higher adherence to the World Cancer Research Fund/American Institute for Cancer Research (WCRF/AICR) guidelines for cancer prevention [10] is associated with lower mortality in CRC survivors [11, 12] and better health-related quality of life [13, 14]. A healthy diet low in fat, meat and refined grains, combined with a high level of physical activity, has been shown to be associated with lower recurrence and mortality rates and a decreased risk of 
comorbid conditions in cancer survivors in general $[11,13$, $15]$ and specifically in CRC survivors [16, 17].

Although the diagnosis of cancer is seen as a teachable moment [18], an event which presents a good opportunity for learning something about a particular aspect of life, only a minority of CRC survivors change their diet after diagnosis. Results from a cross-sectional study in 1458 CRC survivors showed that only $36 \%$ of CRC survivors reported that they had changed their diet after diagnosis [19]. Another crosssectional study in 1196 CRC survivors found that $32 \%$ of CRC survivors intended to adopt a healthier diet; however, only $25 \%$ changed their diet after diagnosis of CRC. This study also found that CRC survivors' adherence to the WCRF/AICR guidelines for cancer prevention was low, with 9\% adhering to the recommendation for fruit and vegetable intake, and $12 \%$ adhering to more than six out of eight recommendations [20].

It is unknown why only few CRC survivors change their diet after diagnosis and why low adherence to healthy lifestyle recommendations persists even after a cancer diagnosis. One hypothesis is that CRC survivors think they already follow a healthy diet, as was seen by Anderson et al., where cancer survivors were sceptical that poor diet caused cancer, because people believed their diets were healthy before onset [21]. Another hypothesis is that CRC survivors do not believe nutrition can have an effect on cancer and cancer outcomes, possibly due to poor nutritional information provision. Two studies among CRC survivors found that only $17-19 \%$ of survivors received advice on nutrition or supplement use [17, 18].

The aim of the current study is (1) to investigate CRC survivors' beliefs on nutrition and cancer and their association with information provision on nutrition by health professionals, (2) to investigate the association between the kind and number of health professionals and the strength of beliefs and (3) to categorize foods that CRC survivors believed either had a positive or negative influence on their cancer.

\section{Methods}

\section{Study design and study population}

The PROCORE study, started in 2016, is a prospective population based study, in which newly diagnosed CRC survivors are recruited before the start of treatment and followed via the PROFILES-registry (Patient Reported Outcomes Following Initial treatment and Long term Evaluation of Survivorship) [22] until 2 years after diagnosis. Ethical approval for the study was obtained from the certified Medical Ethics Committee of Medical Research Ethics Committees United (approval number NL51119.060.14). All respondents gave informed consent. Data from this longitudinal study will be available online for noncommercial scientific research, subject to study question, privacy and confidentiality restrictions and registration (www. profilesregistry.nl). For this specific paper, data from baseline (e.g. pre-treatment) and data from 4 weeks after surgery were used.

Respondents were recruited from four Dutch hospitals: the Catharina Hospital in Eindhoven, Maxima Medical Centre in Veldhoven, Elkerliek Hospital in Helmond and ElisabethTweeSteden Hospital in Tilburg. Inclusion criteria were the diagnosis of CRC stage I-IV and being 18 years or older. Exclusion criteria were ever being diagnosed with a different carcinoma, except for basal cell carcinoma of the skin; having cognitive limitations or being unable to read or write Dutch, which did not allow them to independently fill out a questionnaire.

\section{Data collection}

CRC patients were identified by the research nurses or case managers (depending on hospital). They informed patients about the study and asked them to participate, before start of the treatment. Patients received an information package from the nurse or case manager, including a letter, a patient information leaflet, an informed consent form and a questionnaire. The informed consent and questionnaire could be send back to the PROFILES registry in two separate envelopes. Patients could indicate if they wanted to receive the follow-up questionnaires in digital form via the PROFILES registry, or on paper. Patients were reassured that nonparticipation had no consequences for their follow-up care or treatment.

A total of 595 people recently diagnosed with CRC were invited to participate in the PROCORE study. Of those, 403 people filled out the baseline questionnaire. Of these respondents, 344 underwent surgery for their CRC and were sent the second questionnaire, which was filled out by 326 survivors.

\section{Questionnaires}

For the current research question, data was obtained from the baseline survey and from the survey 4 weeks after surgery. The baseline survey before surgery consisted of self-designed questions on general characteristics, including age, height, usual body weight, body weight at the moment of diagnosis, highest level of education (elementary school, high school, vocational education, bachelor degree), smoking (current smoker, non-smoker, former smoker) and on alcohol consumption (current drinker (with mean intake), former drinker, never). The questionnaire 4 weeks after surgery consisted of self-designed questions on nutritional information provision by health professionals, and patients' beliefs that nutrition influences feelings of well-being, complaints after treatment, recovery and cancer recurrence. Depending on the question, answers could be indicated on an ordinal Likert scale with four options (not at all, a little, some, a lot), on a scale from 0 to 10 , or could be answered with 'yes' or 'no'. Two open-ended questions were included asking the respondents to mention 
foods, diets or supplements they believed to either positively or negatively affect cancer.

Patients' sociodemographic and clinical information was retrieved from the Netherlands Cancer Registry (NCR), including gender, diagnosis and tumour staging.

\section{Data analyses}

Personal and disease-related characteristics, percentage of respondents who received nutritional information and percentage of respondents who strong, intermediate or do not believe that nutrition can influence feelings of well-being, complaints after treatment, recovery after treatment and cancer recurrence were described for the total group of respondents $(n=326$; Tables 1 and 2). To investigate whether strong believers on one belief are also strong believers on the other beliefs, the characteristics of the study population were also split out by the belief of the influence of nutrition on well-being using the following categories: no belief of an influence (score 0-2, $n=$ 63), an intermediate belief (score 3-6, $n=78$ ) and a strong belief (score 7-10, $n=171$ ). Differences between the 'no belief', 'intermediate belief' and 'strong belief' groups were analysed using Chi-square test.

Furthermore, the association between the kind and number of health professionals and the strength of beliefs was investigated.

For the different health professionals, the Likert scale option 'none' was recoded into received information 'no' and a little/some/a lot into 'yes'. Usual body weight and body weight and height at the moment of diagnosis were used to calculate weight change before diagnosis and body mass index (BMI) at diagnosis. For survivors $<70$ years old, a BMI 20-25 was considered a healthy BMI, for survivors $\geq 70$ years old, a BMI 22-28 was considered a healthy BMI [23, 24]. The Global Leadership Initiative on Malnutrition (GLIM) states for survivors $>70$ years old, a BMI $<22$ is a low body mass index, which results in a higher risk for a mild to moderate deficit in muscle mass [23]. BMI 22.01-28 corresponded to not undernourished in people aged $>70$, as stated by the team of the SNAQ RC [24].

To evaluate the association between the dependent variables having strong beliefs on the influence of nutrition on feelings of well-being (yes/no), complaints after treatment (yes/no), recovery after treatment (yes/no) and cancer recurrence (yes/no), and (1) having received nutritional information (yes/no), and (2) the number of health professionals providing nutritional information, prevalence ratios (PRs) and 95\% confidence intervals were calculated. Cox proportional hazard regression analysis was used with the time variable set at 1 for each respondent. Having a strong belief corresponded to a score of 7-10 (scale 0-10) and having no strong belief corresponded to a score of $0-2$ (scale 0 10). Analyses were adjusted for age and gender. Educational level (elementary school/high school; vocational education; bachelor degree or higher), smoking status (current, former or non-smoker), comorbidities $(0,1$ or $\geq 2)$, stage (I, II, III or IV) and BMI at diagnosis (underweight, normal weight, overweight or obese) were evaluated as possible confounding factors and were included if they changed the PR by at least $10 \%$. For strong beliefs that nutrition influences complaints and recurrence, cancer stage changed the PR with $>10 \%$. Therefore, the Cox proportional hazard regression analyses were adjusted for age, gender and cancer stage.

Foods that respondents believed either had a positive or negative influence on their cancer were categorized.

Analyses were performed using SPSS (version 23) and $p<0.05$ was considered statistically significant.

\section{Results}

As can be seen in Table 1, the oldest respondents and respondents with a lower level of education had the least belief on the influence of nutrition on feelings of well-being. Respondents with a high intake of alcohol, respondents with the highest levels of weight loss and with the most comorbidities had the strongest belief. Respondents with a strong belief on the influence of nutrition on feelings of well-being had more often received information from one or more health professionals (Table 2) and were less often obese than survivors who believed there was no influence (Table 1).

A total of 125 respondents (38\%) did not receive information about nutrition from their healthcare professionals (Table 2). Of the respondents who received information about nutrition $(n=$ 201, $62 \%), 41 \%$ received information from one health professional ( $41 \%$ from a nurse, $36 \%$ from a dietician and $23 \%$ from a doctor), $37 \%$ of two health professionals ( $72 \%$ from a doctor and nurse, $11 \%$ from a doctor and dietician and $17 \%$ from a nurse and dietician) and $21 \%$ of three health professionals. No differences were seen in ratings of the different beliefs and whether the information was provided by a doctor, a nurse or a dietician.

Respondents, who received nutritional information from a health professional, had stronger beliefs on the feelings of well-being, the influence of nutrition on recurrence of cancer, recovery after treatment and complaints, compared with respondents who received no nutritional information (Fig. 1 and Table 3). People, who had strong beliefs on the influence of nutrition on well-being, also had strong beliefs about the influence of nutrition on the recovery after treatment, recurrence after cancer and complaints.

People, who received no information from health professionals, had the least beliefs nutrition influences well-being, complaints, recovery after treatment or recurrence. People, who received information from more health professionals, had stronger beliefs (Fig. 2 and Table 3).

Ninety-one respondents (28\%) believe there are nutrients and diets that can positively influence the course of the disease the CRC. Nutrients and diets mentioned by respondents to have a 
Table 1 General characteristics of the total group of respondents $(n=326)$ and split in three groups based on the score for "belief that nutrition influences feelings of well-being"

\begin{tabular}{|c|c|c|c|c|}
\hline & $\begin{array}{l}\text { Respondents } \\
(n=326)\end{array}$ & $\begin{array}{l}\text { Score } 0-2 \\
\text { No belief influence } \\
(n=63) \\
n(\%)\end{array}$ & $\begin{array}{l}\text { Score } 3-6 \\
\text { Intermediate belief influence } \\
(n=78) \\
n(\%)\end{array}$ & $\begin{array}{l}\text { Score } 7-10 \\
\text { Strong belief influence } \\
(n=171) \\
n(\%)\end{array}$ \\
\hline \multicolumn{5}{|l|}{ Gender } \\
\hline Male & $198(61)$ & $42(67)$ & $41(53)$ & $107(63)$ \\
\hline Female & $128(39)$ & $21(33)$ & $37(47)$ & $64(37)$ \\
\hline Age Years $($ mean $\pm \mathrm{SD})$ & $67.2(8.9)$ & $68.8(8.4)$ & $66.9(9.2)$ & $66.2(8.8)$ \\
\hline$<70$ years & $191(59)$ & $32(51)$ & $43(55)$ & $112(65)$ \\
\hline$\geq 70$ years & $135(41)$ & $31(49)$ & $35(45)$ & $59(35)$ \\
\hline \multicolumn{5}{|l|}{ Highest level of education* } \\
\hline Elementary school/High school & $108(33)$ & $28(44)$ & $30(38)$ & $43(25)$ \\
\hline Vocational education & $130(40)$ & $20(32)$ & $30(38)$ & $76(44)$ \\
\hline Bachelor degree or higher & $81(25)$ & $11(17)$ & $18(23)$ & $50(29)$ \\
\hline Missing & $7(2)$ & $4(6)$ & $0(0)$ & $2(1)$ \\
\hline \multicolumn{5}{|l|}{ Smoking } \\
\hline Current smoker & $31(10)$ & $6(10)$ & $5(6)$ & $17(10)$ \\
\hline Former smoker & $181(56)$ & $36(57)$ & $43(55)$ & $94(55)$ \\
\hline Non-smoker & $98(30)$ & $19(30)$ & $25(32)$ & $51(30)$ \\
\hline Missing & $16(5)$ & $2(3)$ & $5(6)$ & $9(5)$ \\
\hline \multicolumn{5}{|l|}{ Alcohol consumption } \\
\hline Never & $59(18)$ & $14(22)$ & $14(18)$ & $28(16)$ \\
\hline Former drinker & $14(4)$ & $1(2)$ & $4(5)$ & $8(5)$ \\
\hline Yes & $234(72)$ & $46(73)$ & $57(73)$ & $123(72)$ \\
\hline $\begin{array}{l}\text { Mean intake (glasses per week) } \\
\text { (SD) }\end{array}$ & $10(9)$ & $7.3(6)$ & $9.3(10)$ & $10.6(10)$ \\
\hline Missing & $19(6)$ & $2(3)$ & $3(4)$ & $12(7)$ \\
\hline $\begin{array}{l}\text { BMI at diagnosis }\left(\mathrm{kg} / \mathrm{m}^{2}\right)(\text { mean } \pm \\
\mathrm{SD})^{*}\end{array}$ & $26.6(4.1)$ & $27.5(4.0)$ & $26.3(4.5)$ & $26.5(3.9)$ \\
\hline Underweight & $24(7)$ & $4(6)$ & $10(13)$ & $8(5)$ \\
\hline Normal weight & $127(39)$ & $23(37)$ & $31(40)$ & $69(40)$ \\
\hline Overweight & $113(35)$ & $19(30)$ & $19(24)$ & $69(40)$ \\
\hline Obese & $58(18)$ & $17(27)$ & $16(21)$ & $23(14)$ \\
\hline Missing & $4(1)$ & $0(0)$ & $2(3)$ & $2(1)$ \\
\hline \multicolumn{5}{|l|}{ Weight change before diagnosis } \\
\hline$>5 \%$ weight loss & $63(19)$ & $5(8)$ & $14(18)$ & $54(32)$ \\
\hline$>0$ to $\leq 5 \%$ weight loss & $66(20)$ & $15(24)$ & $17(22)$ & $62(36)$ \\
\hline Stable weight & $181(56)$ & $41(65)$ & $42(54)$ & $93(54)$ \\
\hline Weight gain & $14(4)$ & $1(2)$ & $5(6)$ & $6(4)$ \\
\hline Missing & $4(1)$ & $1(2)$ & $0(0)$ & $3(2)$ \\
\hline \multicolumn{5}{|l|}{ Comorbidities } \\
\hline 0 & $68(21)$ & $15(24)$ & $20(26)$ & $31(18)$ \\
\hline 1 & $91(28)$ & $21(33)$ & $19(24)$ & $48(28)$ \\
\hline$\geq 2$ & $166(51)$ & $27(43)$ & $39(50)$ & $91(53)$ \\
\hline \multicolumn{5}{|l|}{ Stage } \\
\hline I & $85(26)$ & $16(25)$ & $18(23)$ & $48(28)$ \\
\hline II & $78(24)$ & $16(25)$ & $13(17)$ & $43(25)$ \\
\hline III & $92(28)$ & $15(24)$ & $28(36)$ & $48(28)$ \\
\hline IV & $10(3)$ & $1(2)$ & $5(6)$ & $4(2)$ \\
\hline Missing ${ }^{\&}$ & $61(19)$ & $15(24)$ & $14(18)$ & $28(16)$ \\
\hline
\end{tabular}


Table 1 (continued)

\begin{tabular}{lllll}
\hline & $\begin{array}{l}\text { Respondents } \\
(n=326)\end{array}$ & $\begin{array}{l}\text { Score 0-2 } \\
\text { No belief influence } \\
(n=63) \\
n(\%)\end{array}$ & $\begin{array}{l}\text { Score 3-6 } \\
\text { Intermediate belief influence } \\
(n=78) \\
n(\%)\end{array}$ & $\begin{array}{l}\text { Score 7-10 } \\
\text { Strong belief influence } \\
(n=171) \\
n(\%)\end{array}$ \\
\hline $\begin{array}{l}\text { Tumour location } \\
\text { Colon }\end{array}$ & $222(68 \%)$ & $39(62)$ & $55(71)$ & $18(23)$ \\
$\begin{array}{l}\text { Rectum/rectum sigmoid } \\
\text { Missing }{ }^{\&}\end{array}$ & $76(23 \%)$ & $15(24)$ & $5(6)$ & $40(24)$ \\
\hline
\end{tabular}

${ }^{\&}$ Cancer registry is not yet complete, so these respondents are not registered yet. $* p<0.05$ between the three groups of beliefs

positive influence were a healthy diet with plenty of fruits and vegetables $(n=43)$, fibres $(n=10)$, supplements $(n=9)$, curcumin $(n=8)$, protein-rich foods $(n=7)$, fresh products $(n=$ 4), cannabidiol $(n=3)$, little meat $(n=2)$ and a diet that influences the immune system $(n=2)$.

A total of 114 respondents $(35 \%)$ believe there are nutrients and diets that can negatively influence the disease. Nutrients and diets mentioned by respondents to have a negative influence were too much fat $(n=37)$, red and processed meat $(n=31)$, alcohol $(n=24)$, sugar $(n=20)$, additives $(n=8)$, burned foods $(n=6)$, processed foods $(n=6)$, salt $(n=5)$, an unhealthy diet $(n=4)$, fibre $(n=1)$, protein $(n=1)$ and vitamins $(n=1)$ (data not shown).

Table 2 Information provision and beliefs on the influence of nutrition of the total group of respondents $(n=326)$ and split in three groups based on the score for "belief that nutrition influences feelings of well-being"

\begin{tabular}{|c|c|c|c|c|}
\hline & Respondents $(n=326)$ & $\begin{array}{l}\text { Score } 0-2 \\
\text { No belief influence } \\
(n=63) \\
n(\%)\end{array}$ & $\begin{array}{l}\text { Score } 3-6 \\
\text { Intermediate belief } \\
\text { influence }(n=78) \\
n(\%)\end{array}$ & $\begin{array}{l}\text { Score } 7-10 \\
\text { Strong belief influence } \\
(n=171) \\
n(\%)\end{array}$ \\
\hline \multicolumn{5}{|c|}{ Information provision* } \\
\hline Yes & $201(62)$ & $24(38)$ & $56(72)$ & $119(70)$ \\
\hline No & $125(38)$ & $39(62)$ & $22(28)$ & $52(30)$ \\
\hline \multicolumn{5}{|c|}{ Number of health professionals* } \\
\hline 0 & $125(38)$ & $39(62)$ & $22(28)$ & $52(30)$ \\
\hline 1 & $83(26)$ & $13(21)$ & $23(30)$ & $46(27)$ \\
\hline 2 & $75(23)$ & $7(11)$ & $20(26)$ & $47(28)$ \\
\hline 3 & $43(13)$ & $4(6)$ & $13(17)$ & $26(15)$ \\
\hline \multicolumn{5}{|c|}{ Beliefs recovery after treatment* } \\
\hline $0-2$ & $74(24)$ & $49(78)$ & $13(17)$ & $12(7)$ \\
\hline $3-6$ & $69(22)$ & $10(16)$ & $36(46)$ & $23(14)$ \\
\hline $7-10$ & $169(54)$ & $4(6)$ & $29(37)$ & 135 (79) \\
\hline \multicolumn{5}{|c|}{ Beliefs recurrence of cancer* } \\
\hline $0-2$ & $123(40)$ & $53(84)$ & $27(35)$ & $42(25)$ \\
\hline $3-6$ & $113(36)$ & $9(14)$ & $38(49)$ & $66(39)$ \\
\hline $7-10$ & $75(24)$ & $1(2)$ & $13(17)$ & $60(36)$ \\
\hline \multicolumn{5}{|c|}{ Beliefs complaints* } \\
\hline $0-2$ & $133(43)$ & $61(97)$ & $29(37)$ & $43(25)$ \\
\hline $3-6$ & $92(30)$ & $2(3)$ & $43(55)$ & $47(28)$ \\
\hline $7-10$ & $85(27)$ & $0(0)$ & $6(8)$ & $79(47)$ \\
\hline
\end{tabular}

${ }^{*} p<0.05$ between the three groups of beliefs

\section{Discussion}

Most respondents who received information strongly believe nutrition influences feelings of well-being and recovery after treatment. No differences were found in the ratings of the different beliefs and whether the information was provided by a doctor, a nurse or a dietician. Nevertheless, it did matter how many health professionals provided nutritional information: survivors who received information from three health professionals had more often strong beliefs than those who received information from one health professional. 
Fig. 1 Nutritional information provision (yes/no) and beliefs that nutrition can influence feelings of well-being, complaints, recovery after treatment and recurrence of cancer

\section{Nutritional information provision: Yes}

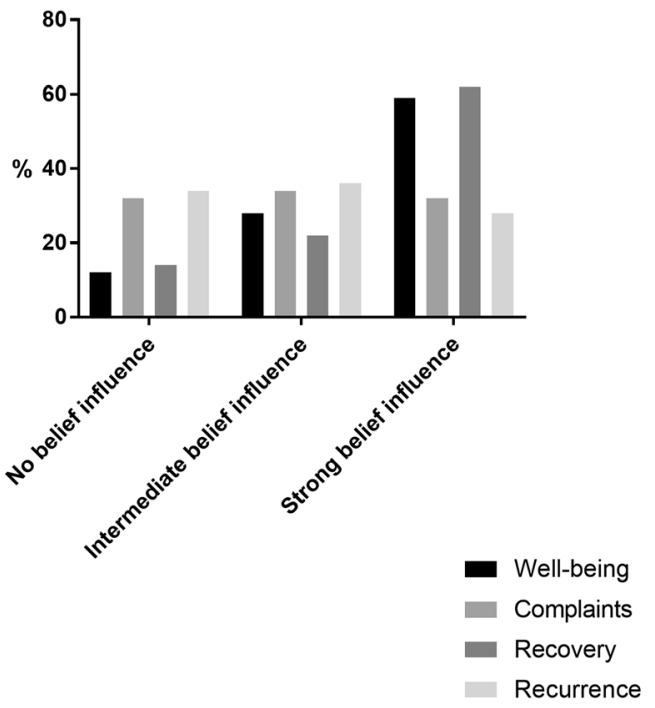

Nutritional information provision: No
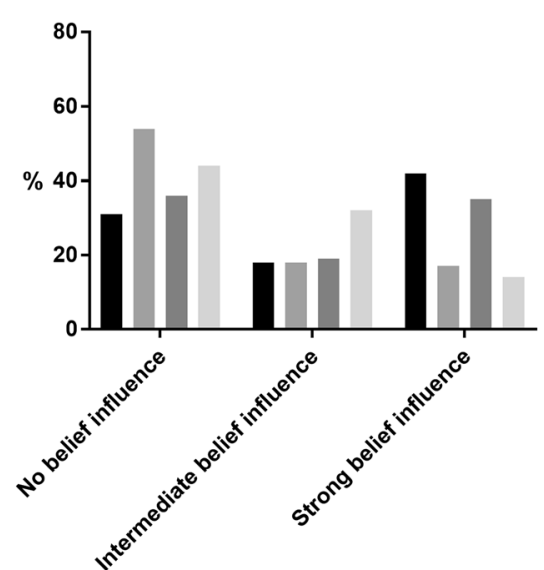

Weaver et al. [25] described that experiments in psychology showed that an opinion is likely to be more widely shared the more different group members express it. Participants had stronger beliefs when the same opinion was expressed once by each of three different group members than when it was expressed once by one group member [25]. In a previous study of our research group, we found that the preferred way of receiving information in a group of cancer survivors was from multiple health professionals: (oncology) nurses, dieticians and doctors, at four or more times [26]. The wish for repeated information provided by different health professionals as expressed in the previous study matches the association found in the current study. Since $59 \%$ of respondents received information from two or more health professionals in the present study, it is important to provide uniform information, to have a maximal effect of repetition, as is also supported by Weaver et al. [25].

No association was seen between the strength of beliefs and the kind of health professional who provided the information. No previous literature was found on this association. In a best-worst discrete choice experiment by Wright et al., CRC survivors expressed the wish to receive dietary information in a hospital by a bowel cancer nurse, which was preferred beyond information from a dietician or a general nurse [27]. In a survey among $175 \mathrm{CRC}$ survivors, $93 \%$ indicated they wanted a conversation with their doctor about survivorship information. Sixty-six percent had received information about diet and exercise to keep them healthy, and of these people $94 \%$ found the information useful [28]. Focus groups with CRC survivors showed that they wish to receive lifestyle support in hospital, offered by a gastro-intestinal oncology nurse, an oncology dietician and/or a stoma nurse specialist. Oncologists were also mentioned to be suitable to offer or to refer to lifestyle support [29]. A survey held among young cancer survivors (mean age 20 years) showed the preferred sources of dietary information were websites and health professionals, without mentioning what kind of health professional [30]. In The Netherlands, every cancer survivor meets

Table 3 Association between having strong beliefs and having received nutritional information or the number of health professionals providing nutritional information

Prevalence ratio's (95\% CI) of having a strong belief that nutrition influences

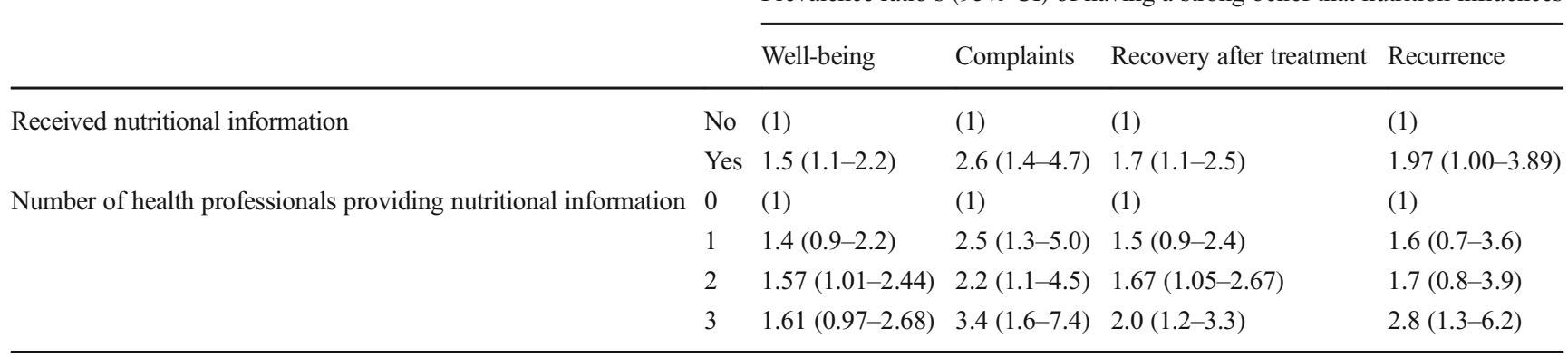

All adjusted for age, gender and cancer stage 


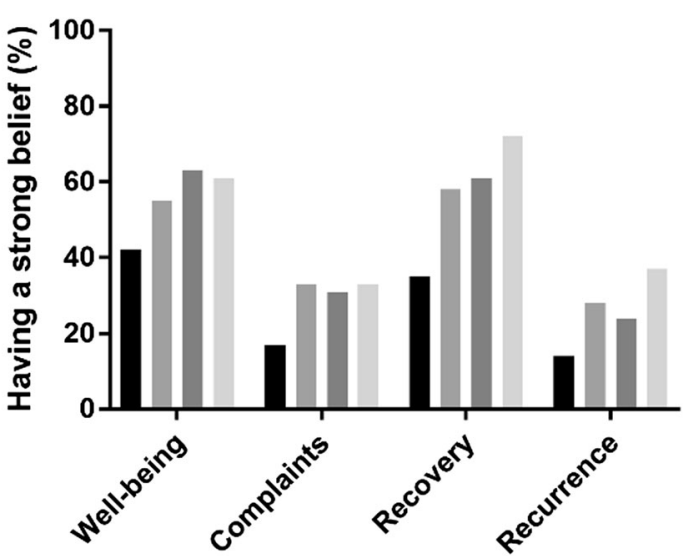

- Number of health professionals providing information: 0

Number of health professionals providing information: 1

Number of health professionals providing information: 2

Number of health professionals providing information: 3

Fig. 2 The number of health professionals providing information and the percentage of respondents having a strong belief

with the doctor and oncology nurse. Nutritional counselling by a dietician is only possible after referral.

The beliefs on foods that can positively or negatively influence the disease are mostly correct. There is indeed evidence that a diet rich in fruits, vegetables and fibres can positively influence cancer outcomes, and too much fat, red and processed meat, alcohol, much sugar, burned foods and an unhealthy diet may negatively influence the risk of cancer recurrence [31]. However, supplements, curcumin and cannabidiol do not positively influence the disease to our current knowledge. The use of supplements during chemotherapy or radiotherapy may even be counter-effective, since antioxidants may counteract the oxidative effect of chemotherapy and radiotherapy $[32,33]$.

A large part of the present study population is overweight or obese at diagnosis, which is in line with other studies [5], who also show that weight gain during and after cancer treatment in specific cancer types (e.g. breast and colorectal cancer) is very common. The conventional belief that weight gain is good and weight loss is bad during and after cancer treatment may not be in place [34].

The present study is one of the first studies investigating the association between nutritional information provision and patients' beliefs on nutrition and cancer. Previous studies often focused on a broad range of topics on information provision to cancer survivors, such as environmental pollution, stress [35, 36], but not on patients' beliefs on nutrition in association with information provision. Major strengths of our study are the link with the Netherlands Cancer Registry and the structured way of sending out questionnaires by the PROFILES registry. In this way, clinical information can be extracted from the Cancer Registry, instead of having to ask for this information in a questionnaire, the latter being more prone to errors. The assessment of information provision by different health professionals is another strength, not focusing on one type of health professional.

There were also some limitations. Due to the short time between the questionnaire and the writing of this manuscript, not all clinical data was registered in the Netherlands Cancer Registry. There is always a delay between the diagnosis of cancer and appearance in the Netherlands Cancer Registry. In the current study, this led to a number of missing values in tumour location and stage. Second, survivors have been actively recruited by oncology nurses and could not be recruited if they were already participating in another study. This may have led to the inclusion of a specific survivor population, because of the inclusion criteria of the other studies. The age and sex distribution of our study population indeed shows that we have a specific survivor population, since our population included more men (61\% vs. $56 \%$ ) and younger patients (59\% vs. $50 \%<70$ years old) compared with the Netherlands Cancer Registry population of 2016 [2]. Recruitment took place in four hospitals, which is a selection of peripheral hospitals in the region. A third limitation is that the authors did not know what kind of nutritional information was given to the cancer survivors by the health professionals. It might be possible that not all advice given was according to the latest insights and knowledge. Other studies did report about the provided advice: participants reported to have received the advice to gain weight by eating whatever they liked, and that they were not discouraged to eat unhealthier foods. This was in contrast with the advice that should have been provided in this study. Also, exercise was not encouraged by nurses in this study, while this was part of the study programme. Patients with a stoma had been told to eat bland low-fibre foods, which is not in line with the dietary guidelines $[6,37,38]$.

Another limitation is that our study was based on crosssectional data, so nothing can be concluded about causal relationships between the provision of nutritional information and changes in beliefs on the effect of nutrition on cancer recurrence, recovery, feelings of well-being and complaints. A last limitation is the relatively short study duration, of 4 weeks. In this timeframe, shortly after diagnosis, most advice will be on surgical recovery, on nutritional needs related to a stoma and digestion problems [37]. In the weeks and months after the completion of acute treatments, nutritional needs may include advice on protein intake, weight loss or weight gain, diarrhoea, xerostomia, anorexia and food aversion [6].

\section{Conclusion and recommendations}

The current study shows that it is important for cancer survivors to receive information about nutrition and cancer, since it might positively influence cancer survivors' beliefs on the effect of 
nutrition on cancer recurrence, recovery, feelings of well-being and complaints. Repeating the information by different health professionals is important in strengthening correct beliefs on nutrition and cancer. The beliefs on foods that can positively or negatively influence the disease are mostly correct.

Future research should focus on whether it is more important to have the same message repeated by one health professional several times, or that the same message is spread by different health professionals. We speculate that in patient care, several health professionals should bring the same message to the patient, to confirm the information already given. This might be the solution in altering nutritional beliefs and thereby altering nutritional behaviour of CRC survivors. To make sure that every health professional brings the same message, it is important to make one person (e.g., a dietician) responsible for keeping the other health professionals up to date about evidence- or practicebased nutritional advices and changes in these advices. Furthermore, the dietician must take the lead in arranging the procedure concerning nutritional screening (when and by whom), which basic advice can be given and by whom and when patients need to be referred. All given dietary advice and used information sources must be registered in the patient file. In this way, all health professionals can refer to this information source and inform the survivor in a uniform manner.

Funding information This study was financially supported by Alpe d'HuZes/Dutch Cancer Society (award number: IKZ 2012-5426) to Sandra Beijer, $\mathrm{PhD}$.

\section{Compliance with ethical standards}

Conflict of interest The authors declare that they have no conflict of interest.

Research involving human participants Ethical approval for the study was obtained from the certified Medical Ethics Committee of Medical Research Ethics Committees United (approval number NL51119.060.14).

Informed consent Informed consent was obtained from all individual participants included in the study.

Open Access This article is distributed under the terms of the Creative Commons Attribution 4.0 International License (http:// creativecommons.org/licenses/by/4.0/), which permits unrestricted use, distribution, and reproduction in any medium, provided you give appropriate credit to the original author(s) and the source, provide a link to the Creative Commons license, and indicate if changes were made.

\section{References}

1. WCRF. 2016; Available from: http://www.wcrf.org/int/cancerfacts-figures/data-specific-cancers/colorectal-cancer-statistics. Accessed 31-1-2019
2. Netherlands Cancer Registry managed by the Netherlands Comprehensive Cancer Organisation. Cijfers over kanker. March 2018; Available from: http://www.cijfersoverkanker.nl/. Accessed 31-1-2019

3. Brouwer $\mathrm{N}$ et al (2018) An overview of 25 years of incidence, treatment and outcome of colorectal cancer patients. Int J Cancer 143(11):2758-2766

4. Marzorati C, Riva S, Pravettoni G (2017) Who is a cancer survivor? A systematic review of published definitions. J Cancer Educ 32(2): 228-237

5. Winkels RM, Snetselaar T, Adriaans A, van Warmerdam LJC, Vreugdenhil A, Slooter GD, Straathof JW, Kampman E, van Lieshout R, Beijer S (2016) Changes in body weight in patients with colorectal cancer treated with surgery and adjuvant chemotherapy: an observational study. Cancer Treat Res Commun 9:111-115

6. Vogel, J.B. S.; Delsink, P.; Doornink, N.; Ten Have, H.; Van Lieshout, R. (2016), Handboek Voeding bij Kanker. 2nd ed. 750

7. Komurcu S, Nelson KA, Walsh D (2014) The gastrointestinal symptoms of advanced cancer. Support Care Cancer 9(1):32-39

8. Tong H, Isenring E, Yates P (2009) The prevalence of nutrition impact symptoms and their relationship to quality of life and clinical outcomes in medical oncology patients. Support Care Cancer 17(1):83-90

9. Arends J, Bachmann P, Baracos V, Barthelemy N, Bertz H, Bozzetti F, Fearon K, Hütterer E, Isenring E, Kaasa S, Krznaric Z, Laird B, Larsson M, Laviano A, Mühlebach S, Muscaritoli M, Oldervoll L, Ravasco P, Solheim T, Strasser F, de van der Schueren M, Preiser JC (2017) ESPEN guidelines on nutrition in cancer patients. Clin Nutr 36(1):11-48

10. World Cancer Research Fund and American Institute for Cancer Research (2007) Food, nutrition, physical activity, and the prevention of cancer: a global perspective. AICR, Washington DC

11. Inoue-Choi M, Robien K, Lazovich D (2013) Adherence to the WCRF/AICR guidelines for cancer prevention is associated with lower mortality among older female cancer survivors. Cancer Epidemiol Biomark Prev 22(5):792-802

12. Van Blarigan EL et al (2018) Association of survival with adherence to the American Cancer Society Nutrition and Physical Activity Guidelines for Cancer Survivors after colon cancer diagnosis: the CALGB 89803/Alliance trial. JAMA Oncol 4(6):783790

13. Inoue-Choi M, Lazovich DA, Prizment AE, Robien K (2013) Adherence to the World Cancer Research Fund/American Institute for Cancer Research recommendations for cancer prevention is associated with better health-related quality of life among elderly female cancer survivors. J Clin Oncol 31(14):1758-1766

14. Breedveld-Peters JJ et al (2018) Colorectal cancers survivors' adherence to lifestyle recommendations and cross-sectional associations with health-related quality of life. Br J Nutr 120(2):188-197 $1-10$

15. Doyle C, Kushi LH, Byers T, Courneya KS, Demark-Wahnefried W, Grant B, McTiernan A, Rock CL, Thompson C, Gansler T, Andrews KS, 2006 Nutrition, Physical Activity and Cancer Survivorship Advisory Committee, American Cancer Society (2006) Nutrition and physical activity during and after cancer treatment: an American Cancer Society guide for informed choices. CA Cancer J Clin 56(6):323-353

16. Meyerhardt JA, Sato K, Niedzwiecki D, Ye C, Saltz LB, Mayer RJ, Mowat RB, Whittom R, Hantel A, Benson A, Wigler DS, Venook A, Fuchs CS (2012) Dietary glycemic load and cancer recurrence and survival in patients with stage III colon cancer: findings from CALGB 89803. J Natl Cancer Inst 104(22):1702-1711

17. Rock CL, Doyle C, Demark-Wahnefried W, Meyerhardt J, Courneya KS, Schwartz AL, Bandera EV, Hamilton KK, Grant B, McCullough M, Byers T, Gansler T (2012) Nutrition and 
physical activity guidelines for cancer survivors. CA Cancer J Clin 62(4):243-274

18. Demark-Wahnefried W, Aziz NM, Rowland JH, Pinto BM (2005) Riding the crest of the teachable moment: promoting long-term health after the diagnosis of cancer. J Clin Oncol Off J Am Soc Clin Oncol 23(24):5814-5830

19. Bours MJ, Beijer S, Winkels RM, van Duijnhoven FJ, Mols F, Breedveld-Peters JJ, Kampman E, Weijenberg MP, van de PollFranse LV (2015) Dietary changes and dietary supplement use, and underlying motives for these habits reported by colorectal cancer survivors of the Patient Reported Outcomes Following Initial Treatment and Long-Term Evaluation of Survivorship (PROFILES) registry. Br J Nutr 114(2):286-296

20. Winkels RM, van Lee L, Beijer S, Bours MJ, van Duijnhoven FJB, Geelen A, Hoedjes M, Mols F, de Vries J, Weijenberg MP, Kampman E (2016) Adherence to the World Cancer Research Fund/American Institute for Cancer Research lifestyle recommendations in colorectal cancer survivors: results of the PROFILES registry. Cancer Med 5(9):2587-2595

21. Anderson AS, Steele R, Coyle J (2013) Lifestyle issues for colorectal cancer survivors-perceived needs, beliefs and opportunities. Support Care Cancer 21(1):35-42

22. van de Poll-Franse LV et al (2011) The Patient Reported Outcomes Following Initial treatment and Long term Evaluation of Survivorship registry: scope, rationale and design of an infrastructure for the study of physical and psychosocial outcomes in cancer survivorship cohorts. Eur J Cancer 47(14):2188-2194

23. Cederholm T et al (2019) GLIM criteria for the diagnosis of malnutrition-a consensus report from the global clinical nutrition community. J Cachexia Sarcopenia Muscle 10(1):207-217

24. Kruizenga $\mathrm{H}$ et al (2010) The SNAQ RC, an easy traffic light system as a first step in the recognition of undernutrition in residential care. J Nutr Health Aging 14(2):83-89

25. Weaver K, Garcia SM, Schwarz N, Miller DT (2007) Inferring the popularity of an opinion from its familiarity: a repetitive voice can sound like a chorus. J Pers Soc Psychol 92(5):821-833

26. van Veen MR et al (2018) Nutritional information provision to cancer patients and their relatives can promote dietary behavior changes independent of nutritional information needs. Nutr Cancer 70(3):483-489 1-7

27. Wright SJ, Gibson D, Eden M, Lal S, Todd C, Ness A, Burden S (2017) What are colorectal cancer survivors' preferences for dietary advice? A best-worst discrete choice experiment. J Cancer Surviv 11(6):782-790

28. Salz T, Baxi SS, Blinder VS, Elkin EB, Kemeny MM, McCabe MS, Moskowitz CS, Onstad EE, Saltz LB, Temple LKF, Oeffinger KC
(2014) Colorectal cancer survivors' needs and preferences for survivorship information. J Oncol Pract 10(4):e277-e282

29. Hoedjes M, de Kruif A, Mols F, Bours M, Beijer S, Winkels R, Westerman MJ, Seidell JC, Kampman E (2017) An exploration of needs and preferences for dietary support in colorectal cancer survivors: a mixed-methods study. PLoS One 12(12):e0189178

30. Pugh G, Hough RE, Gravestock HL, Jackson SE, Fisher A (2017) The health behavior information needs and preferences of teenage and young adult cancer survivors. J Adolesc Young Adult Oncol 6(2):318-326

31. World Cancer Research Fund/American Institute for Cancer Research. Diet, nutrition, physical activity and cancer: a global perspective. Continuous Update Project Expert Report 2018; Available from: http://www.dietandcancerreport.org. Accessed 62-2019

32. Fuchs-Tarlovsky V (2013) Role of antioxidants in cancer therapy. Nutrition 29(1): 15-21

33. Yasueda A, Urushima H, Ito T (2016) Efficacy and interaction of antioxidant supplements as adjuvant therapy in cancer treatment: a systematic review. Integr Cancer Ther 15(1):17-39

34. Anderson AS, Caswell S, Wells M, Steele RJC (2013) Obesity and lifestyle advice in colorectal cancer survivors-how well are clinicians prepared? Color Dis 15(8):949-957

35. Shahab L et al (2018) Prevalence of beliefs about actual and mythical causes of cancer and their association with socio-demographic and health-related characteristics: Findings from a cross-sectional survey in England. Eur J Cancer 103:308-316

36. Zaharek-Girgasky MM et al (2015) Diet-related colorectal cancer prevention beliefs and dietary intakes in an urban minority population. J Community Health 40(4):680-685

37. Macleod M et al (2018) Feasibility study to assess the delivery of a lifestyle intervention (TreatWELL) for patients with colorectal cancer undergoing potentially curative treatment. BMJ Open 8(6): $\mathrm{e} 021117$

38. Anderson AS, Caswell S, Wells M, Steele RJC, MacAskill S (2010) "It makes you feel so full of life" LiveWell, a feasibility study of a personalised lifestyle programme for colorectal cancer survivors. Support Care Cancer 18(4):409-415

Publisher's note Springer Nature remains neutral with regard to jurisdictional claims in published maps and institutional affiliations. 